\title{
Maggot Infestation of the Prolapsed Uterus
}

\author{
Muhammad Hamza ${ }^{1}$, Tahira Yasmeen ${ }^{2}$, Noor Fatima ${ }^{1}$, Irfan Ahmed Nadeem ${ }^{1}$ \\ 1. Surgery, Al Noor Surgery Hospital, Chakwal, PAK 2 . Gynecology and Obstetrics, Holy Family Hospital, Rawalpindi, \\ PAK
}

Corresponding author: Muhammad Hamza, mhamza7593@gmail.com

\section{Abstract}

Myiasis of the genital organ is a rare clinical entity. It is a very disturbing condition that is linked to poor hygiene and sanitary conditions. Here, we report a case of a 62 -year-old postmenopausal female who presented with the complaint of a mass coming out of the vaginal orifice for 10 years. Recently, for the last five months, the mass had become irreducible, ulcerated, and infested with maggots. A vaginal hysterectomy was performed, which provided immediate relief to the patient.

Categories: Obstetrics/Gynecology, Urology, Public Health

Keywords: uterus, prolapsed uterus, myiasis, pelvic organ, cervix, hysterectomy, hygiene, maggot

\section{Introduction}

Infestation of living humans by maggots of flies is known as myiasis. These insects live on host tissue and body fluids $[1,2]$. They can cause severe infection, inflammatory reaction, and can be linked to psychiatric disturbances [3,4]. Commonly, cutaneous, ophthalmic, auricular, and nasopharyngeal myiases are seen, with genital myiasis being a rare condition [3]. Here, we present a case of myiasis of the prolapsed uterus. It is a rare case that requires attention. It is probably the first case from Pakistan to be reported in the literature.

\section{Case Presentation}

A 62-year-old postmenopausal female, para 3, presented with a complaint of a mass coming out of the vaginal orifice for the last 10 years. Initially, there were no symptoms but recently in the last five months, the mass had become irreducible, and she developed dysuria. She had no history of any previous illness or allergy. There was no family history of malignancies. There was no significant family or psychosocial history.

The patient was weak and fragile. Her systemic examinations were unremarkable except for the mass coming out from the vaginal orifice (Figures 1-2).

Review began 11/02/2018

Review ended 11/03/2018

Published 11/06/2018

๑) Copyright 2018

Hamza et al. This is an open access

article distributed under the terms of the

Creative Commons Attribution License

CC-BY 3.0., which permits unrestricted

use, distribution, and reproduction in any medium, provided the original author and source are credited.

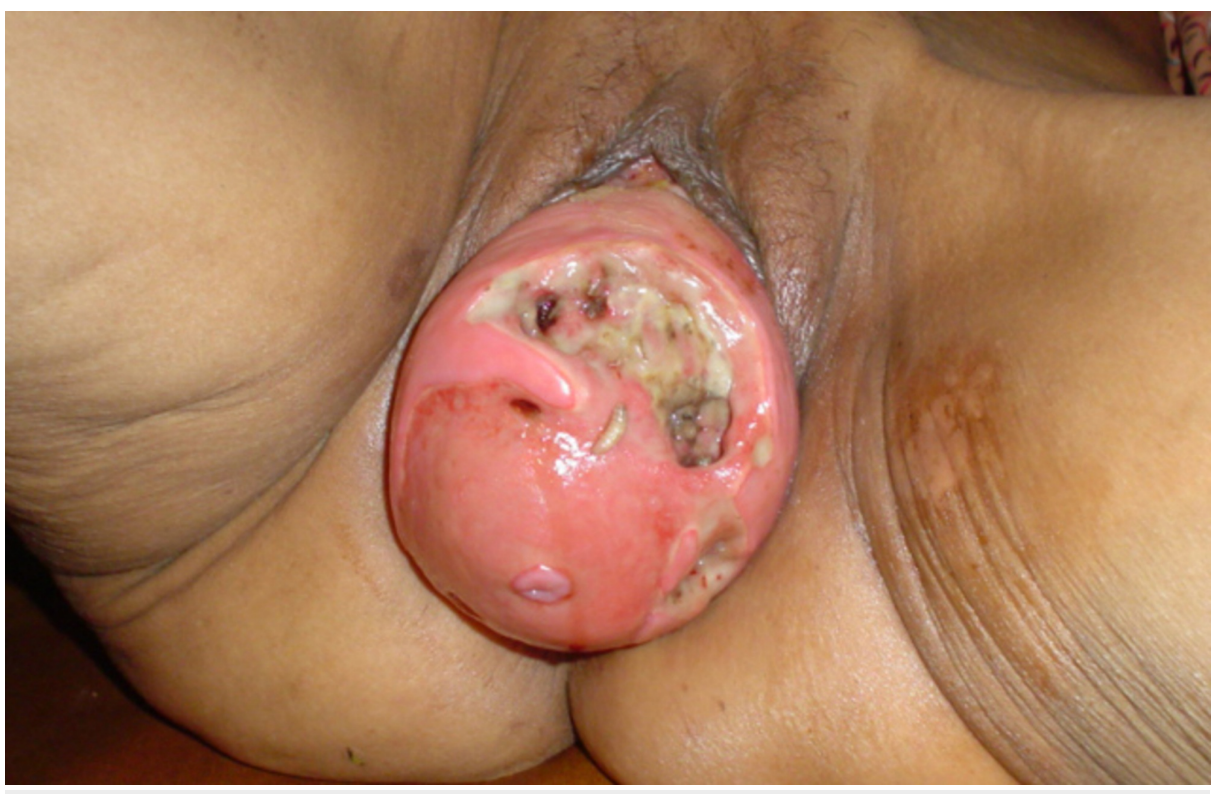

FIGURE 1: Maggot Infestation of the Prolapsed Uterus 


\section{Cureus}

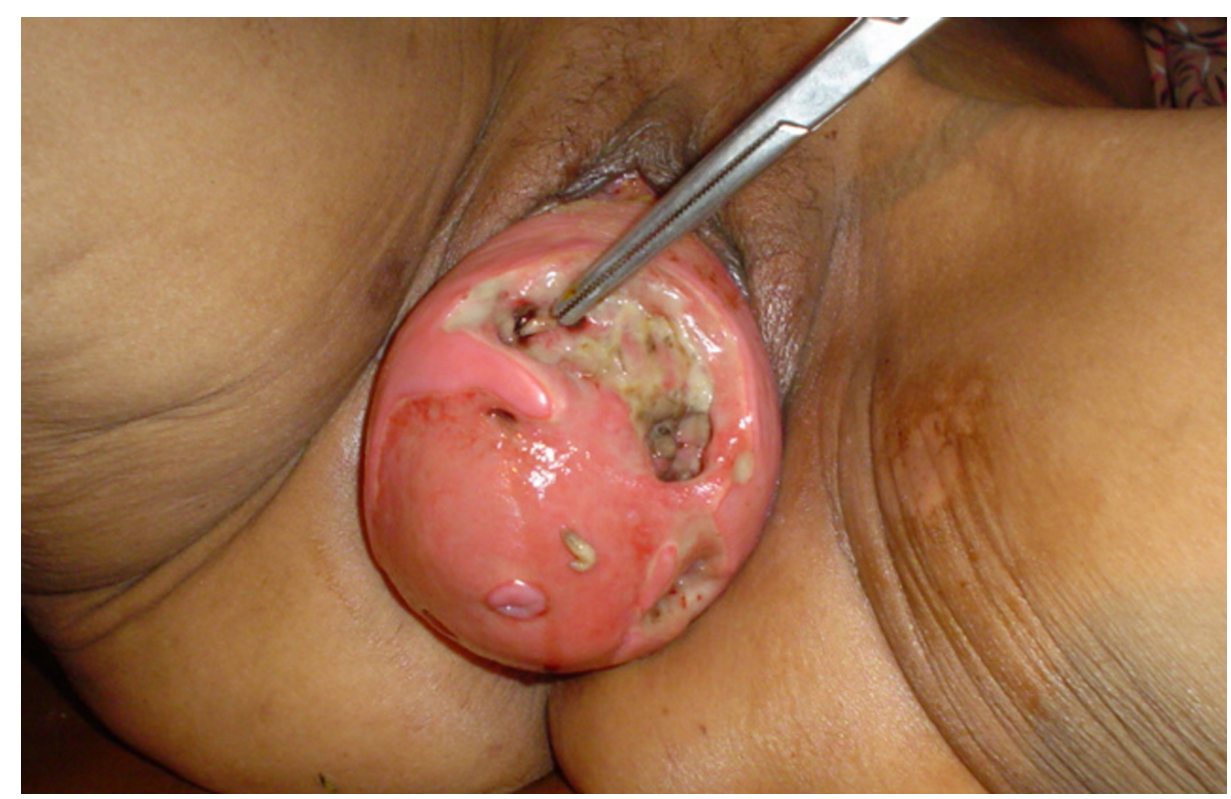

FIGURE 2: Maggot Infestation of the Prolapsed Uterus

Her vitals were normal. A genital and vaginal examination revealed an irreducible uterovaginal prolapse with maggots, larvae, and eggs. Ulcers were seen over the prolapsed mass.

Further investigation of the patient revealed that her hemoglobin, total leucocyte count (TLC), platelet count, partial thromboplastin time (PTT), activated partial thromboplastin time, blood sugar levels, and urine analysis were in normal range. Hepatitis B and C profiles were negative.

The patient was treated with analgesic and broad-spectrum antibiotics. The treatment options were presented to the patient with proper counseling. Vaginal hysterectomy was selected and informed consent was obtained. There were no intraoperative and postoperative complications. The histopathology report excluded malignancy. The symptoms resolved completely after the surgery. The patient was discharged and went back to routine life.

\section{Discussion}

Myiasis is the parasitic infestation of a living organism by flies or insects. Commonly, they involve the nose (81\%), ear (11\%), tracheostomy wound (5\%), gums and serous cavities (1\%), face (1\%). Genital myiasis is a very rare condition $[1,2]$. Kasinathan et al., Ray et al., and Saldarriaga et al. mention different cases of uterovaginal prolapse with myiasis, which were treated successfully $[1,2,5]$. Purnima et al. in their study have reported a similar condition in a middle-aged female with mental ill health [3]. Vulval myiasis has also been reported in the literature [6]. Baidya et al. have reported this entity in the female with cervical and vaginal malignancy, respectively [4]. However, in our patient, the histopathology report excluded malignancy. The ulcers were most probably because of the friction and exposure to the external environment.

Many substances like chloroform and turpentine oil (1:4), ether, hydrogen peroxide, ethylene chloride, lidocaine have been mentioned in the literature for treatment of myiasis. Removal of these larvae is difficult, challenging, and time-consuming [2]. We treated the patient with broad-spectrum antibiotics, analgesics, and performed definitive surgical treatment with vaginal hysterectomy. It provided immediate relief to the patient and she had no complication. The patient returned to normal life. We did not use antilarval medicine as it was deemed unnecessary considering that the affected part was removed by surgery.

The major predisposing factors leading to a parasitic infestation of a living organism is old age, lack of mobility, poor hygiene, prolapsed organ, ulcerative lesion, etc [1-5]. Most of these factors were present in our patient. Good hygiene is necessary to avoid a maggot infestation. Moreover, health education in developing countries like Pakistan is very important. These measures will protect individuals from many diseases that are common in this region.

\section{Conclusions}

Myiasis of the genital organ is a rare clinical entity. Good hygiene and proper sanitary conditions are very important for the prevention of myiasis. Vaginal hysterectomy is the definitive treatment option that can 


\section{Cureus}

provide immediate relief to the patient.

\section{Additional Information}

\section{Disclosures}

Human subjects: Consent was obtained by all participants in this study. Conflicts of interest: In compliance with the ICMJE uniform disclosure form, all authors declare the following: Payment/services info: All authors have declared that no financial support was received from any organization for the submitted work. Financial relationships: All authors have declared that they have no financial relationships at present or within the previous three years with any organizations that might have an interest in the submitted work. Other relationships: All authors have declared that there are no other relationships or activities that could appear to have influenced the submitted work.

\section{References}

1. Kasinathan A, Shanthini NF: Uterovaginal prolapse with myiasis: a case report . Int J Reprod Contracept Obstet Gynecol. 2014, 3:477-478. 10.5455/2320-1770.ijrcog20140643

2. Ray S, Basak S, Konar H: Maggots in prolapsed uterus - polluted progress of life style . Med J Armed Forces India. 2012, 68:240-1.

3. Purnima U, Varshney U, Jahan M: A rare case of genital myiasis in a woman with psychiatric disturbance . CHRISMED J Health Res. 2017, 4:55-8. 10.4103/2348-3334.196069

4. Baidya J: A rare case of genital myiasis in a woman with genital prolapse and malignancy and review of the literature. Ann Trop Med Public Health. 2009, 2:29-30.

5. Saldarriaga W, Herrera E, Castro D: Myasis in uterine prolapse, successful treatment . Am J Obstet Gynecol. 2011, 205:e5-e6. Accessed: October 15, 2008: 10.1016/j.ajog.2011.03.019

6. Pandey D, Divedi P, Mishra PK, Mishra P: Vulval myiasis: an unusual presentation of a rare entity in an adolescent female. Trop Parasitol. 2015, 5:58-60. 10.4103/2229-5070.149924 